\title{
Case-control study of the association between kava use and ischaemic heart disease in Aboriginal communities in eastern Arnhem Land (Northern Territory) Australia
}

\author{
A R Clough, Z Wang, R S Bailie, C B Burns, B J Currie
}

J Epidemiol Community Health 2004;58:140-141

$\mathrm{K}$ ava, (Piper methysticum Forst. f., "Intoxicating pepper"), is a consciousness-changing muscle relaxant consumed in the Pacific islands and, since 1982, by indigenous Australians in eastern Arnhem Land (Northern Territory, NT) using dried powder imported from Fiji or Tonga. ${ }^{1}$ Very heavy use was widespread in Arnhem Land during the 1990s. ${ }^{1}$ Circumstantial evidence suggests that kava consumption is associated with ischaemic heart disease (IHD) and sudden cardiac deaths among, particularly, young Aboriginal sportsmen in this population. ${ }^{2}$

\section{METHODS}

In a case-control study, cases comprised 83 people admitted to hospital for the first time during 1992-1997 from the region with a medical officer's confirmed diagnosis of IHD (ICD9 Codes 4100-4149). Of these, 25 were admitted on more than one occasion. Up to four randomly selected controls $(n=302)$ were matched with each case for age, sex, and home locality. NT registries indicated that a further 20 people with no record of hospital admission died with IHD during 1992-1997. These were matched with 75 controls. Comprehensive data were not available to identify IHD morbidity before 1992 .

Methods to measure exposure to kava use, alcohol, tobacco, petrol sniffing, cannabis use, and other possible confounding factors, data analysis techniques, and ethics approvals have been described elsewhere. ${ }^{3}$

\section{RESULTS}

Adjusting for confounders, odds ratios (OR) for kava use before or during 1992-97 changed from 1.41 (95\% CI 0.73 to $2.73, \mathrm{p}=0.303)$ to $1.51(0.75$ to $3.05, \mathrm{p}=0.247)$ (table 1$)$. There was no residual confounding effect of age in the multivariate model $(\mathrm{OR}=1.50,0.74$ to 3.04$),\left(\chi^{2}=0.23\right.$, likelihood ratio test, $\mathrm{p}=0.635)$. There was no association with kava use in just those communities where kava had been used for up to 15 years (adjusted $\mathrm{OR}=1.75,0.82$ to $3.74, \mathrm{p}=0.140$ ) or when those admitted on more than one occasion $(\mathrm{n}=25)$ were compared with their matched controls $(\mathrm{n}=132) \quad$ (adjusted $\mathrm{OR}=2.24,0.65$ to 7.68 , $\mathrm{p}=0.191)$.

Twenty who died from IHD without hospital admission and 75 matched controls were combined with 83 known admissions and 302 matched controls. No association with kava use was found (adjusted $\mathrm{OR}=1.44,0.78$ to 2.66, $\mathrm{p}=0.245$ ) so the results of the analysis of IHD admissions alone were probably not influenced by survival bias.

While the expected association between IHD and tobacco use was not found in the univariate analysis (table 1), it appeared when 36 cases were compared with 158 controls who had no record of kava, alcohol, cannabis, or petrol use $(\mathrm{OR}=3.96,1.08$ to $14.49, \mathrm{p}=0.021)$.

\section{DISCUSSION}

There was no clear evidence for an association between kava use and IHD. Twice the risk of IHD was the smallest detectable risk $(80 \%$ power, $95 \% \mathrm{CI})$ in this study. Further research is warranted given the non-significant tendency for approximately $50 \%$ increased risk of IHD found in kava users and given the lack of information about kava's effects.

It is not known if an association between kava use and IHD would develop in time. Results of a recent cross sectional study in one community did not support this, as serum concentrations of markers of thrombolytic processes and carotid arterial wall thicknesses were no different in those who had used kava for 1-18 years (median 12 years) when compared with nonusers. ${ }^{1}$ Moreover, kava has been used for centuries by Pacific peoples with no evidence for an association with heart disease.

In Aboriginal kava drinkers, disrupted lipid profiles and tendencies for raised HDL-cholesterol and LDL-cholesterol, ${ }^{1}$ are not clearly indicative of increased atheroma risk.

Aboriginal sportsmen who may already have established IHD may be at higher risk of cardiac events if heavy kava use accompanies vigorous exercise. Heavy kava users may become dehydrated and myocardial ischaemia and sudden cardiac death are possible attributable to abnormal coagulation with increased thrombosis and/or arrhythmias. ${ }^{2}$

Acute effects of kava may also be mediated by neurological mechanisms. Large doses of kava pyrones can lead to abnormal atrioventricular function, consistent with kava's well known muscle relaxing properties. ${ }^{4}$ Actions of kava pyrones on voltage gated ion channels, with antagonistic effects on $\mathrm{Na}^{+}$and $\mathrm{Ca}^{2+}$ currents and modulation of $\mathrm{K}^{+}$currents, are of importance for their mood stabilisation properties and these cellular actions show a large overlap with the actions of established mood stabilising drugs. ${ }^{4}$ Antipsychotic drugs prolong QTc interval and bind to the potassium rectifier channel, and their use may be associated with torsades de pointes and sudden cardiac death. ${ }^{5}$ Similar outcomes with kava use should be considered especially in Aboriginal kava drinkers who may already suffer abnormalities in cardiac output or effective mechanical performance.

\section{ACKNOWLEDGEMENTS}

The authors wish to thank the National Health and Medical Research Council who funded this research and declare that the paper's publication creates no financial or professional conflict of interest. In addition thanks to Alcan Gove (formerly Nabalco Corporation), Gemco Semancor, Territory Health Services, NT Department of Education, Dr Len van Ingen, Dr Bill Lax and Mary Mackay at Gove District Hospital, Dr Wendy Page, Jenness Warin, Aboriginal Health Workers and other clinicians in eastern Arnhem Land clinics: Terrence Guyula, Maymuna Yunupingu, Joaz Wurramarrba, Helen Lalara, Lazarus Mamarika, Barbara Dhaminy, Joan Djamalaka, Susan Ninikirri, Sylvia Rrepula, Julie Djinathi, Janice Nundhirribala, Roslyn Wunungmurra, Robyn Dixon, Jenni Langrell, Lynn Murphy, Virginia Risser. 
Table 1 Odds ratios and 95\% confidence intervals for the association between IHD and kava use and other substance use

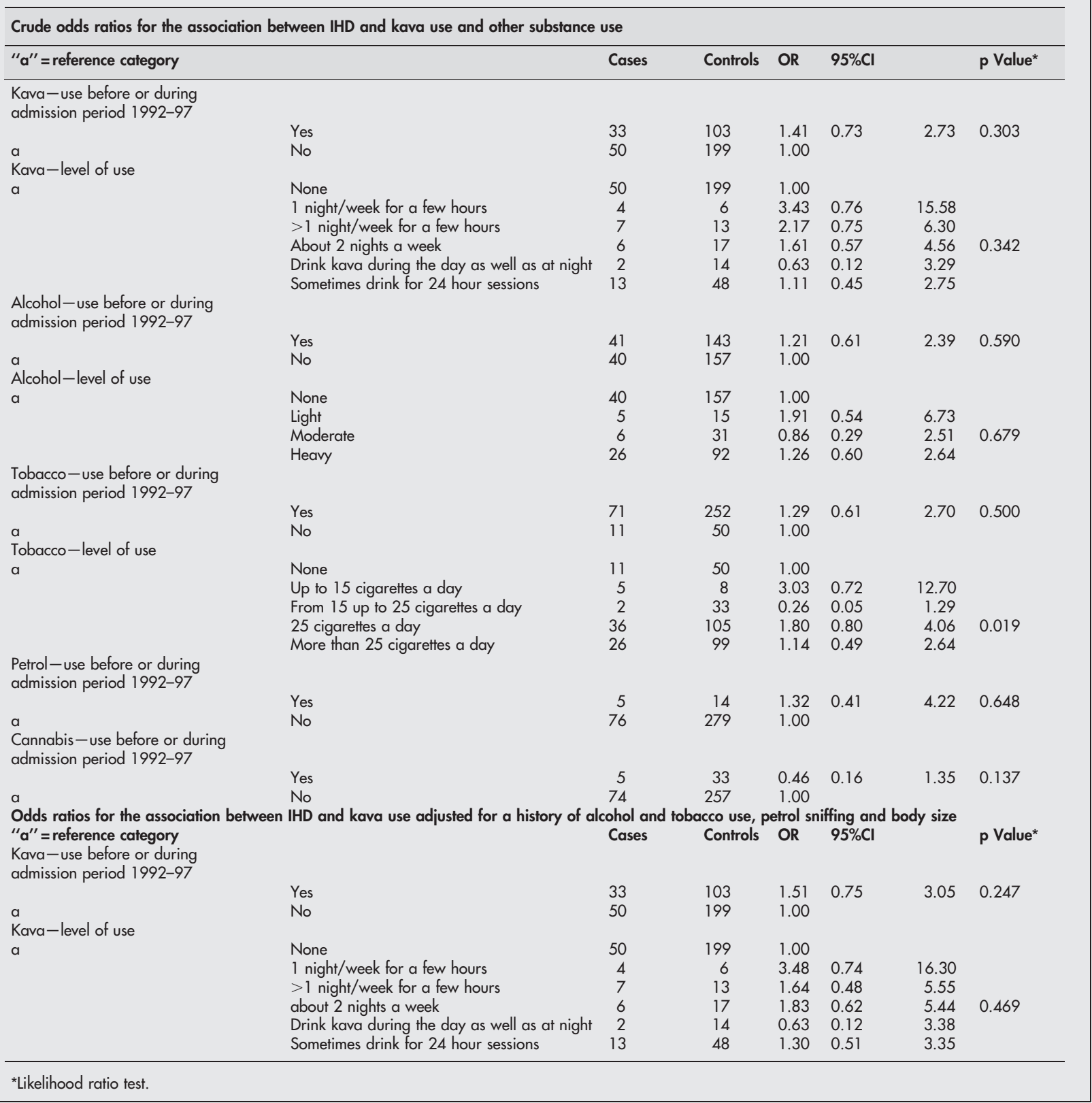

\section{Authors' affiliations}

A R Clough, Menzies School of Health Research and Northern Territory University, Darwin, NT, Australia

Z Wang, C B Burns, Menzies School of Health Research, Darwin, NT R S Bailie, Menzies School of Health Research and Flinders University, NT Clinical School

B J Currie, Menzies School of Health Research \& NT Clinical School, Darwin, NT

Correspondence to: $\mathrm{Dr}$ A Clough, c/o Northern Territory University, PO Box 1479, Nhulunbuy, NT, 0881, Australia; Alan.Clough@nt.gov.au

Accepted for publication 8 July 2003

\section{REFERENCES}

1 Clough AR, Jacups SP, Wang Z, et al. Health effects of kava use in an eastern Arnhem Land community. Intern Med J 2003;33:336-40.

2 Young $M$, Fricker $P$, Thomson $N$, et al. Sudden death due to ischaemic heart disease in young Aboriginal sportsmen in the Northern Territory, 1982-1986. Med J Aust 1999; 170:425-8.

3 Clough AR, Bailie R, Burns CB, et al. Validity and utility of community health workers' estimation of kava use. Aust NZ J Public Health 2002;26:52-7.

4 Grunze H, Langosch J, Schirrmacher K, et al. Kava pyrones exert effects on neuronal transmission and transmembraneous cation currents similar to established mood stabilizers - a review. Prog Neuropsychopharmacol Biol Psychiatry 2001;25:1555-70.

5 Glassman AH, Bigger JT. Antipsychotic drugs: prolonged QTc interval, torsades de pointes, and sudden death. Am J Psychiatry 2001;158:1774-82. 